\title{
Bilateral subdiaphragmatic kidneys with right-sided renal malrotation
}

\author{
Al Shaimaa Fathi Elshetry* (1)
}

\begin{abstract}
Background: The subdiaphragmatic kidney is a positional variant of the uncommon cephalad renal ectopia, whereas renal malrotation refers to the anomalous renal hilar position. Both anomalies are rare, possibly under-reported, discovered incidentally on radiological examinations since patients are often asymptomatic.

Case presentation: This case report presents a unique renal anatomical variation in a 71-year-old female patient. A bilateral subdiaphragmatic renal ectopia coupled with right-sided renal malrotation, discovered accidentally on abdominal ultrasound (US), and confirmed by abdominal magnetic resonance imaging (MRI).
\end{abstract}

Conclusions: The presented case of bilateral subdiaphragmatic kidneys associated with right-sided renal malrotation is rare and not previously described in the literature. Radiologists must be familiar with these renal anomalies that can be discovered on imaging performed for other indications. MRI can provide more anatomical data compared to US.

Keywords: Subdiaphragmatic kidney, Cephalad renal ectopia, Renal malrotation, Renal anomaly, Abdominal MRI, Ultrasound

\section{Background}

Cephalad renal ectopia is uncommonly reported renal anomaly; correspondingly, it is considered the rarest type of renal ectopy, and its subdiaphragmatic type is scarce $[1,2]$. Renal malrotation is also a rare condition that often develops in association with renal ectopia [2].

High renal ectopia was commonly reported in males and on the left side. Unilateral subdiaphragmatic kidney had been reported as an isolated developmental anomaly, discovered incidentally on routine imaging evaluating other conditions [1,3-5]. Parmar et al. [6] reported an instance of bilateral subdiaphragmatic kidneys in a 5-year-old boy associated with a ventral hernia and omphalocele.

Cephalad renal ectopia and renal malrotation, without urinary tract complications, are benign conditions, often asymptomatic, and discovered accidentally, contributing to underestimate their actual incidence $[1,7]$. In most

*Correspondence: shaimaafathi2020@gmail.com

Radio-Diagnosis Department, Faculty of Human Medicine, Zagazig

University, Zagazig, Egypt cases, renal structure and function are normal, so surgery or biopsy is not required [6].

Despite being a rare condition, the possibility of subdiaphragmatic renal ectopy should be considered if a kidney is not seen at its normal position, and in the differential diagnosis of thoracic masses in chest radiography $[5,6]$. Similarly, in the case of renal malrotation, a pelvic mass that could displace the kidney and rotate its hilum should be excluded [2].

The present case of bilateral subdiaphragmatic kidneys combined with right-sided renal malrotation is probably the first of its kind. Searching the literature revealed no similar case of these anomalies in combination.

\section{Case presentation}

A 71-year-old female patient with chronic intermittent right-sided upper abdominal pain was referred to the radiology department. A routine abdominal ultrasound showed that both kidneys were in a higher position than normal, behind the liver and the spleen (Fig. 1a, b). High renal ectopia was suspected. Right-sided renal malrotation was also noticed (Fig. 1b). Hepato-splenomegaly and 


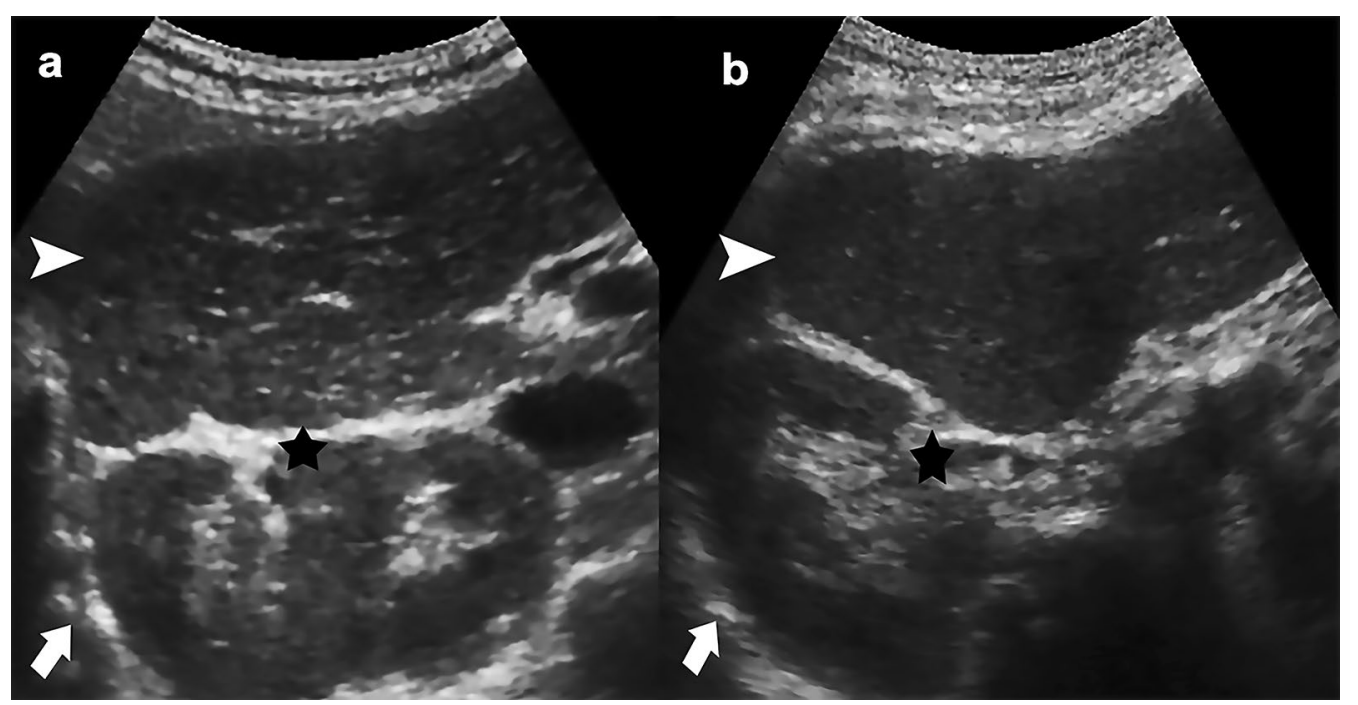

Fig. 1 a Sagittal ultrasound image showing the subdiaphragmatic position of the right kidney (thick arrow) posterior to the liver (arrowhead) with anteriorly located right renal hilum (star). b Sagittal ultrasound image showing the subdiaphragmatic location of the left kidney (thick arrow) posterior to the spleen (arrowhead) with normally located left renal hilum (star)

solitary gallbladder (GB) stone with GB wall thickening were the other observations. No other abdominal lesions were identified.

A week later, an abdominal magnetic resonance imaging (MRI) scan was performed. Bilateral subdiaphragmatic renal ectopia was confirmed; both kidneys were located below the diaphragm, postero-superior to the liver, and the spleen (Fig. 2a). Right-sided renal malrotation was observed, with the right renal hilum directed anteriorly (Fig. 2b), whereas the left renal hilum was normal in position (Fig. 2c). The size of both kidneys was average. The diaphragm was intact and normal in position with no evidence of diaphragmatic defects or eventration. Moderate enlargement of both liver and spleen and GB wall thickening with a single GB stone were detected. No other abdominal abnormalities were observed. According to the imaging findings, the symptom of the patient was not related to the presented renal anomalies. Most probably, chronic calcular cholecystitis was the cause of her symptom.

\section{Discussion}

During embryological development, both kidneys lie in the pelvis. At sixth to ninth weeks of gestation, each kidney gradually migrates cephalad from the pelvis to reach its renal fossa. During the renal ascent, both kidneys rotate 90 -degree antero-medially, and the hila become directed medially [2].

A high renal ectopia is assumed as a congenital anomaly in the absence of traumatic diaphragmatic defects [8]. It occurs due to excessive cephalad renal migration during renal development. Usually, renal rotation is complete with normally positioned renal hilum and pelvis [2]. Furthermore, high renal ectopy may develop after birth; Zolotas and Krishnan [8] reported an interesting case of post-natal subdiaphragmatic migration of the right kidney in a 3-month male infant.

Renal malrotation results from defective rotation of the kidney and its hilum during renal cranial migration [9]. It frequently occurs in association with renal ectopy; however, isolated cases still happen [2]. Renal malrotation was classified into four types depending on the renal hilum position:

Type 1: non-rotation, the renal hilum is located in the ventral position

Type 2: incomplete rotation, the renal hilum has a variable position between the normal medial and ventral positions

Type 3: reverse rotation, the hilum is directed laterally

Type 4: hyper-rotation, the hilum is positioned posteriorly. Non-rotation and incomplete rotation are the most common types [7].

In the presented case, the right kidney had undergone non-rotation as its renal hilum faces anteriorly. The diagnosis of renal malrotation and most ectopic kidney cases can be achieved on abdominal imaging [2, 7]. As previously reported, bilateral subdiaphragmatic kidneys were discovered on abdominal ultrasound [6]. MRI provides high-resolution anatomical details that significantly 

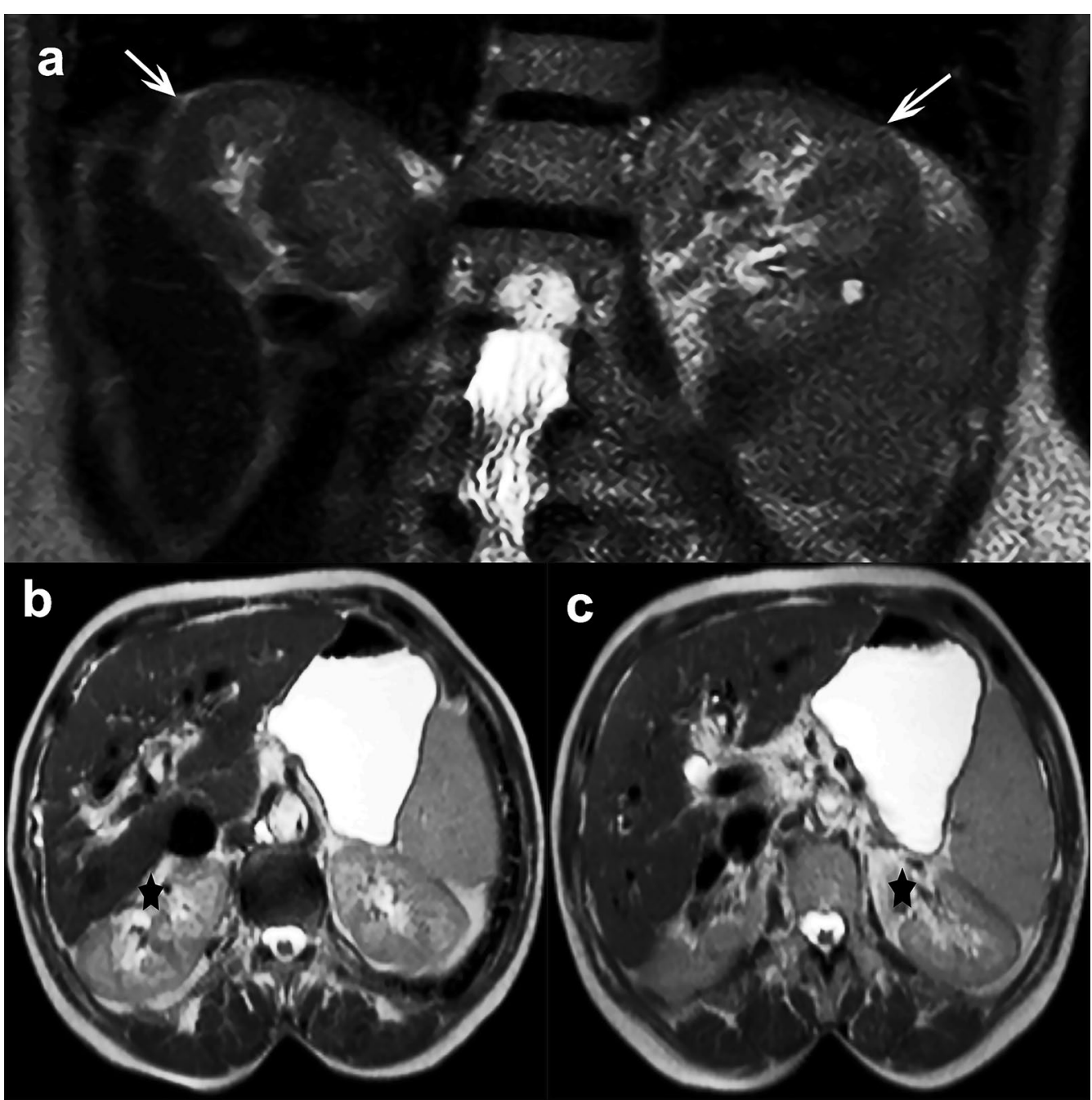

Fig. 2 a Coronal T2-weighted MR image demonstrating the subdiaphragmatic position of both kidneys (white arrows). b Axial T2-weighted MR image demonstrating the anterior direction of the non-rotated right renal hilum (star). c Axial T2-weighted MR image at a higher level, showing the normal medial position of the left renal hilum (star)

improve the evaluation of renal positional and rotational anomalies [10]. In the current case, the sonographic finding of high renal ectopia and right-sided renal malrotation was confirmed by MRI.

This case provides evidence that subdiaphragmatic renal ectopia and renal malrotation can co-exist. This unique and rare constellation of anomalies can be explained by the ultimate association of the processes of renal ascent and rotation during renal organogenesis [2].

\section{Conclusions}

A case of bilateral subdiaphragmatic kidneys associated with right-sided renal malrotation, which has no analogous case in the literature, is presented. The actual incidence of subdiaphragmatic renal ectopia and renal malrotation is indeterminate. However, radiologists must be familiar with these renal anomalies that can be discovered incidentally. MRI can provide more detailed anatomical data compared to US.

\section{Abbreviations}

MRI: Magnetic resonance imaging; GB: Gall bladder.

\section{Acknowledgements}

Not applicable.

\section{Authors' contributions}

The author confirms individual responsibility for manuscript preparation and revision. The author read and approved the final manuscript.

\section{Funding}

Not applicable. 
Availability of data and materials

Not applicable.

\section{Declarations}

\section{Ethics approval and consent to participate}

Approval was obtained from the Research Ethics Committee of the faculty of Human Medicine, Zagazig University. The procedures done in this case report adhere to the tenets of the Declaration of Helsinki, and verbal informed consent was obtained from the patient.

\section{Consent for publication}

The patient gave a written informed consent to publish this case report.

\section{Competing interests}

The author declares that there is no competing interest.

Received: 3 Auqust 2021 Accepted: 16 November 2021

Published online: 24 November 2021

\section{References}

1. Kaur RP, Chawla D (1980) Right subdiaphragmatic kidney. Br J Radiol 53:809-810. https://doi.org/10.1259/0007-1285-53-632-809

2. Kelly CR, Landman J (2012) Normal and abnormal development. In: Kelly CR, Landman J (eds) The netter collection of medical illustrations-urinary system, 2nd edn. Elsevier Saunders, Amsterdam, pp 34-36
3. Kundu AK, Goswami TK (1995) Left subdiaphragmatic kidney: a case report. J Indian Med Assoc 93:153

4. Utangaç MM, Kiliç S, Daggülli M, Söylemez H (2015) Subdiyafragmatik ektopik böbrek: Olgu sunumu. Yeni Üroloji Dergisi 10(1):36-38

5. Hirayama I, Inokuchi R, Fukue M, Doi K (2019) Right subdiaphragmatic renal ectopia mimicking lung tumour. Thorax 74(7):721. https://doi.org/ 10.1136/thoraxjnl-2019-213282

6. Parmar J, Mohan C, Vora M (2016) Cephalad-renal ectopia: Bilateral subdiaphragmatic kidneys in a patient of omphalocele with ventral hernia. Pediatr Urol Case Rep 3:63-67. https://doi.org/10.14534/PUCR.20163 16893

7. Bohm GB (2008) Anomalies of kidney rotation, position and fusion. In: Fotter R (ed) Pediatric uroradiology, 2nd edn. Springer, Berlin, pp 81-87. https://doi.org/10.1007/978-3-540-33005-9_4

8. Zolotas E, Krishnan RG (2016) Subdiaphragmatic renal ectopia: case report and review of the literature. Case Rep Nephrol 2016:1-3. https:// doi.org/10.1155/2016/1084917

9. Jung SII, Cho JY (2012) Congenital anomalies of the upper urinary tract: introduction. In: Kim SH (ed) Radiology illustrated-uroradiology. Springer, Berlin, pp 55-58. https://doi.org/10.1007/978-3-642-05322-1_3

10. Grattan-Smith JD, Jones RA (2008) Diagnostic procedures: MR urography in children. In: Fotter R (ed) Pediatric uroradiology, 2nd edn. Springer, Berlin, pp 17-35. https://doi.org/10.1007/978-3-540-33005-9_1

\section{Publisher's Note}

Springer Nature remains neutral with regard to jurisdictional claims in published maps and institutional affiliations.

\section{Submit your manuscript to a SpringerOpen ${ }^{\circ}$ journal and benefit from:}

- Convenient online submission

- Rigorous peer review

- Open access: articles freely available online

- High visibility within the field

- Retaining the copyright to your article

Submit your next manuscript at $\boldsymbol{\nabla}$ springeropen.com 